\begin{tabular}{ll}
\hline \hline MINING AND METALLURGY INSTITUTE BOR & ISSN: 2334-8836 (Štampano izdanje) \\
UDK: 622 & ISSN: 2406-1395 (Online) \\
\hline \hline
\end{tabular}

UDK: 504.06:330.1(045)=111

doi:10.5937/mmeb1603083L

\author{
Snežana T. Lazović, Katanić Zoran ${ }^{* *}$, Radmilo V. Todosijević ${ }^{* * *}$
}

\title{
ECOLOGY, ECONOMY AND TECHNOLOGICAL CHALLENGES OF THE FUTURE
}

\begin{abstract}
Economic development depends on the used technology. Using the new technology should be to create the conditions on possibilities for improvement the working conditions in order to reduce the environmental pollution; the all in order to increase the labor productivity. Dynamic sustainable development implies harmonization of the environmental development with the principles of social justice atin the global international level.
\end{abstract}

Keywords: ecology, globalization, knowledge, technology

\section{INTRODUCTION}

Development of science and technicaltechnological achievements, complexity of work and life processes, demographic growth, increase of uncertainty and risks, as well as tendency to safeguard and increase the achieved, have impacted the man to tend to foresee and master the facts of the future. Different approaches to the future in different time periods refer to different contexts when the thinkers and philosophers lived and worked. Such thinking about the future refers to certain values and there is no such a way of thinking which might be called highly normative exercise.[3]

Only relative ambiguity allows for freedom of choice. There is no freedom of choice under circumstances of absolute organization. Freedom of a being is a knowledge about freedom. To be means to know. Is the level of freedom increased as the cage gets bigger!? Yes and no, but only in sense of space. You are still inside the cage. There

is no movement, no communication, no freedom. Openness is a path towards freedom and it does not matter whether it is a door or a window. The most important is that there is a way out! There is always a way out, but it has to be found and it is there that we face the man's greatness of ability to get free from destiny. While running away from destiny, we are actually facing it. While going towards it, we control it, solving and making it desired. Here is substantial difference between organized and unorganized man. Some tend towards the order, whereas the others tend towards the chaos. Only chaos is absolute.

We live in a cyber space. The decisive factor for development the activities leading to creation of cyber concept was a war.[8] One reacts faster under circumstances of war danger. Entropy of human psychology does not tolerate emptiness.

Changing a pattern of values, we are actually attempting to change a system of va-

\footnotetext{
* Associate Professor Faculty of Economics in Kosovska Mitrovica

** Doctoral student at the University Singidunum, Belgrade

${ }^{* * * *}$ Faculty of Economics, Subotica, Emeritus
} 
lues. By devaluing the old, we are affirming the new. Preconditions for affirmation of progressive achievements are created.

System becomes flexible, since it simply responds to changes and challenges in its environment.

Intellectual climate was conducive the emergence of the economy based on knowledge. Was the knowledge of economy conducive for development of economy based on knowledge?

Let's get back to the main point. There was a directing through sharp semantic barriers between disciplines to build a more efficient interdisciplinary scientific method of managing complex, stochastic systems and development the general theory of management and communication.

\section{INFORMATION SOCIETY AND GLOBALIZATION}

In relation to the challenges of the future, the cosmological aspect withdraws in front of the anthropological, the man is put in the center of attention, which leads to a shift towards specifically human, psychological and ethical-anthropological issue.

And only when the developed sense of commitment to the future - prognostic-futurological, is caught in the jaws of life with the cosmological approach, reconstructive need will be opened as a necessity, just as the innovative cognitive aspects for defining grandiose visionary as we have felt sometimes in the past and feel now.[5]

It is a process of reshaping the scientific thoughts. The message is to unite knowledge and actions in order to reach the desired future. Even the ancient Greeks were aware of the need for effective strategic management and dealt with anticipation, even through prophecy, with the desire to create a projection about the future of the environment. [3]

Forecasters and futurologists agree that the 21 st century will be marked the achieved level and pace of information technology development with the characteristics of universal diffusion, which will inevitably lead to the emergence of a new social structure - the global information society.

The idea of globalization is not verified by any significant and proven experimental conception of historical development. Globalization is the result of forces powers, which will over time become impotent. There will be a formidable defensive processes.

There will be a reversibility, when we will get things, phenomena and processes back to their original state. Globalization discards uniqueness of civilization development paths, the uniqueness of its experiential, cultural and historical heritage of the total historical heritage.

In their turn, the uniqueness of each civilization development is associated with the peculiarities of formation the leaders and characteristics of educational process, with a help of leaders who bring their ideas to every man.

It seems hardly possible that these characteristics might be globalized now or anytime possible. It is certain that there will be a differentiation of the view on the world, culture, development ... Need to forecast the role of information in development of a society is necessary, both as a factor stimulating development and as a mobilizing force. It is critical that information exchange for the optimal development of the society shall be subjected to management and control. In the basis of the management processes in contemporary circumstances, there is a dominant need to have a new strong educational system, able to absorb, process and distribute the huge volume of information and effectively directs and brings it to the trainee and users in general. In case of absence or unpopularity of some material operation methods in a society, as well as short-term effects of wide range violent methods, information is becoming the dominant means of social influence. 
Contrary to the idea of social globalization, the idea of information society does not contradict anything. The concept of globalization is applicable to social processes in general and the information society, in details, as already addressed, is very conditional. However, it does not mean that Information Society is also conditional.[5]

In general, the information society is one of the variants of the society with service technologies, where the gradual transition towards it is one of the characteristics of modern historical epoch.

The question is not in fact, is there a principle possibility of the information society existence? The issue is something else. Does such a society already exist or is it just a feud of future? Information society cannot be founded in rapid information technology development. It would not correspond to the historical development of human society and civilization. Simple exponential growth and development are not possible in social systems. The gradual approach is inevitable. There are no experiments there.

The establishment of a society or changes within it are historical processes came under the influence of numerous factors. The result of these processes is a complex component of certain economic, political and social relations between people. Information technology itself cannot ensure the emergence of such a complex component. It can only create a part of the infrastructure for the information society, an information environment for its formation, development and existence. However, it is too early to speak what it shall mean for a society some time soon. It is only possible with certain scientific accuracy to predict some characteristics of an information society. At the same time, it turns out that the existing information forces analysts to think not only about the benefits of the information society, but also about its shortcomings. The digital Darwinism is about to start. ${ }^{[6]}$

\section{MODERN TECHNOLOGIES FOR ENVIRONMENTAL PROTECTION}

Use of modern technology is a crucial prerequisite for addressing the current problems of environmental protection. The main objective is to initially an integrate environmental protection in all stages of the production cycle - from production to waste disposal. This includes, for instance, reduction of hazardous waste already in the production process, increase of the functioning level of invested energy, economized investment of resources, the development of alternative and reserve funds that are environment friendly.

Achieving all this is primarily the task of scientists and engineers in science, in business and in government. They can make their own effect on the environment contribute to this, that the technical and scientific progress is again perceived as something more than just something positive. There is a great opportunity for economy in incoming periods of technical development for environmental protection: creativity, innovation on the edge of new challenges create the new economic and social perspectives.

Progressive world tries to define principles of behavior towards the nature. Although most developed countries are in favor (!?), the United Nations Convention on protection the environment has not been signed yet. There have been directives these days obliging the United Kingdom to reduce the level of pollution by $48 \%$, Luxembourg and Belgium by $42 \%$, Italy $36 \%$, Germany, which leads the world in terms of technique and technology, for equipment production and technology, as well as with regards the efforts in legislation, by $28 \%$ and so on. China and America continue to support the environmental pro- 
tection, but still remain the world's greatest polluters.

Germany has a dominant position in the world for export of technologies for environmental protection. Out of total internationally recognized environmental protection patents, $23 \%$ originate from Germany, followed by the US with $15 \%$, and Japan with $10 \%$. Here are some examples where it is possible to effectively implement the achievements of innovative technologies for environmental protection.[4]

Coal gas for heating, obtained by drilling deep coal deposits, independently from mining works for excavation of stone coal. Drill holes up to $1900 \mathrm{~m}$ lead into a layer of stone coal, which contains a large amount of coal gas.

The wind generated energy is produced by the wind turbine generators made by "Sever" from Subotica, with 20 years warranty (!) and whose production in Subotica is being supported by "Siemens" after the disputable privatization process. With the advancement of technology in this field, there will be improvement of performance and an increase in installed power.

Production of electricity from coal in combined power plants with integrated gasification of coal in the world of science is viewed as a technical alternative to conventional gas production of electricity, but with little impact on the environment. The expected increase in the level of action against the new conventional coal plants means carbon dioxide reduction for at least $12 \%$.

Gas and steam turbine power plants with integrated coal gasification has a corresponding lower level of activity in the production of gas by the nature of the losses in the conversion process. Yet it reaches between 45 and $50 \%$ of the efficacy, which is far more than what can be achieved in conventional coal-fired power plants. By coal gasification, any coal can be converted into a fuel gas friendly for the environment While the coal with high melting points is prioritized in conventional power plants, for reasons of environmental protection, any type of coal may be used in gas and steam turbine power plants with integrated coal gasification. Thus, the range of coals suitable for the production of electricity is significantly extended.

The heat of the Earth appears as a natural technical storage for solar energy. However, such accumulated heat cannot be directly used, because it is at too low temperature level to be able to heat the room. 'Heat pump', which works inversely to the principle of refrigerator, takes away the underground heat and rises a level of water temperature to a maximum of 50 degrees. These pumps, although they have to be turned on with the help of other types of energy, provide more than three times as much useful energy.

Solar thermal energy is not accumulated the best in large power plants, but directly at the consumers, because it is easier to cover as much surface as needed for amount of energy demand, for instance by installation on rooftops and facades. Use of technologies and systems for solar energy is expected to expand and we have witnessed a dramatic decline in the price of these systems, as well as increase of their technological efficiency. The absorption plants, which show good levels of operation especially at relatively low operating temperatures, are particularly suitable for heating outdoor pools. Depending on the installation and operation mode of an outdoor swimming pool, it is possible to replace 25 $100 \%$ of outdated energy for heating.

Solar power and solar thermal power plant work on the system of the thermal battery to be able to cover the maximum energy consummation in the evening hours. Energy costs are about $10 \%$ higher in the 
conventional energy production, however saving of the outdated energy sources is on the other side of the cost surplus.

Solar plants as a type of power are far above all other technologies and they works on the principle of flat discs, where plastic cell systems and sensors are placed so that the sun rays are always focused on solar elements regardless of the height of the sun. Daily orientation towards the sun is very simple and is done by simple rotation of one plate on its axis, which lies on a hollow ring to its outer edge and which is located in an annular channel. Completely flat power plant is cheaper, almost with no need for maintenance and does not provide any resistance to the wind and with its distance, it takes up the smallest surface of all known plants."

Energy from deposited gas is produced from garbage dumps. Nowadays, Norway exports waste to Sweden, which produces electricity from it and then exports it to Norway in order to pay off for the imported garbage.

Production process in a steel plant makes it possible to produce carbon dioxide with more than $50 \%$ less hazardous materials per 1 ton than by the usual four-stage system of steel production. Proceeding to a steel plant, where steel scrap melts directly into pure liquid steel, can make a major contribution to environmental protection and maintenance of additional assets. Around the world, the steel scrap is put again into use, which is equivalent to processing of $50 \mathrm{car}$ bodies in a second. Facilities of material combustion are capable to convert chemical energy (any reaction of oxygen with hydrogen or methanol from natural gas, oil or coal) into electricity. The principle approximately corresponds to the chemical electrolysis. For Europe in the $21^{\text {st }}$ century, the

\footnotetext{
*The authors of this study designed and implemented a project of solar power plant in Serbia in 2015, power of $1.54 \mathrm{MW}$, worth 820,000 EUR.
}

scientists have forecast that the market of these facilities will produce $300-800 \mathrm{~mW}$ per year, and since 2010 from 400 to 1400 $\mathrm{mW}$ per year.

Holographic-optical light control with light electricity savings of more than $80 \%$ compared to conventional lighting system.

Technology of old building renovation has produced a combination of heat and radiation termination in flats with the recapture of heat, which consequently has enabled that the total energy consumption of an existing home with four members is reduced by about $60 \%$ and that for at least 8 liters of fuel oil2. This shows that even in old buildings concepts for home energy reduction can be completely implemented.

Constructed buildings with energy saving system have wood as the best building material. It is renewable and environment friendly resource. Small energy costs are presented, as opposed to production of other building materials. At the same time, it is an ideal thermo-insulator for appropriate manner of construction. Research in the field of "double house" made of wood, limestone, bricks and light concrete gave the following results: the wooden house made from prefab construction elements jumped by 46 $\mathrm{kWh}$ of energy for heating 2 per year. On the other side, a German average for conventional building houses is 140 and $200 \mathrm{kWh}$. A new German legislation on heat protection permits maximum $85 \mathrm{kWh}$ for new buildings, almost double value of the one achieved in a wooden house.

\section{MANAGEMENT DIMENSION IN THE WORLD OF WORK}

Presented results of scientific/technical/ technological/biological and other processes of predictions suggest that the world of work has expanded from working on the land to work on oceans and in the cosmos, and that it is gradually transformed from a 
manual, via capital, to intensive research work producing knowledge, experience and skills. In our case, these are the sizes for the growing level of operational readiness, reliability and functional benefits, meaning that our landmarks for the future are more effective technologies and machines.

The world of technologies and machines is growing exponentially in constant development; the world of technologies - machine is following us since the birth of the first thoughts in a human being, through the current period, and further into the fu-ture [10].

Science grows by the law of exponential growth. Science grows similar to the population. Population grows proportionally to the last generation. Science grows proportionally to the mass of knowledge that we have been left by the previous generation. Today there are between 92 and $93 \%$ of all scientists who have ever been engaged in science. All the legacy of the past (although awareness of the late generations governs the heads of the living ones), all Tesla, Einstein, Pupin, ... make only 7 to $8 \%$, but this is a grand legacy. However number of prominent scientists today is consistent percentage of the total number of people who do the science !?

The total number of scientists grow more or less in proportion to the square value of number of prominent scientists. If we want to increase a number of prominent scientists by 5 , we have to increase a total number of scientists by 25 .

On the other hand, the funds are increased for the fourth root of the number of famous scientists. If we increase the number of scientists for 3 times, the funds should be increased by 71 times.

There is no serial production in science. We have found that the number of researchers doubles every 12 years, meaning that in each such interval there will be as many researchers as there were in entire previous period. For the last 60 years, the number of researchers has been increased by 17 times, which corresponds to an exponential development with the doubling period of 12 years.

This exponential growth cannot go on forever because it would come to absurd proportions, since in the real world there would be no conditions for its existence. And system, even the scientific one, which suffers absurd proportions must fall apart. It is therefore essential, and it is imposed by itself, to establish adaptive braking system, because, if development continued at exponential characteristics we would have the situation that there would be 2 million scientists per a million inhabitants in the United States in 200 years, and it simply could not exist.

We have calculated that the braking period is about 30 years. This is essentially the time it takes to master the results of fundamental research, to apply strategic plans and achieve continuity in the developmental research. In the history of science, after a period of braking- "stagnation", the period of development always came, meaning that the period of revolutionary, i.e. exponential growth is coming. We are to prove that in science, there are cycles in terms of development, however, without recourse and stagnation, but the lower limit of the cyclic curve takes place in the level of scientific achievements and abilities of their materialization [5].

The economic system can be studied in the same way as the molecular structure. Interdependence of parts of the system creates a situation where changes in one direction may produce changes in the counterclockwise. This indicates that the equilibrium (balance of system) detects the cyclical development. This is contrary to the prevailing evolution of a certain time. We hereby verify that economy indicates that we are again and again on the verge of increasing demands in terms of radical efforts on securing the life, achieving solutions for unemployment processes, maintaining natio- 
nal aspirations in the survival, in the developed society and providing conditions for the development and maintenance of a high level of education of the population in all areas of economic and social activity.[1] As it may be concluded according to the above mentioned facts, that survival, development and duration of the enterprising processes in time and in given social conditions and changes may have a continuous development of all social activities and this presupposes the development of increasingly sophisticated, better quality, more reliable, more effective technology and machines. This world was and will remain the greatest man's ally. Production of the new values of the material and the spiritual character is, quite certainly, the main driving force of development of each serious society.

\section{EVOLUTIONARY PERFORMANCE OF ECOLOGY AND TECHNOLOGY PROBLEMS}

Researches show that almost every issue in economic development leads towards technology. H. J. Bruton compiled empirical evidence from numerous studies on the technology and concluded that the increased quantity of physical inputs (capital kvalitetra da) is rarely worth more than half of the increase in gross domestic production. Lester Thurow [7] has come to the same conclusion. Rest of increase is a result of increase in productivity based on increasing levels of technical modernity and quality management ${ }^{\dagger}$.

Never before has the environmental movement around the world been so well-

\footnotetext{
$\dagger$ Unfortunately, some people, due to narrow scientific horizons, still discover that the sun rises in the east!? We point out to the models of Kalecki, then Pola Romer from Stanford, and Michael Davidson and their contribution to growth and development, through the implementation of technical progress by raising the level of technical modernity of assets.
}

established, but also has the environmental movement never been so obstructed by advocates of the ecological movement as it is a case now. This attitude comes from the fact that most developed countries outside Europe, opposite of the European developed countries, do not pay enough attention to environmental issues. Their "contribution" consists in the relocation of technologies that pollute the environment outside their space to areas that are geographically very distant from them (one of the characteristics of globalization).

Shortly before the industrial revolution the level of environmental pollution was insignificant. In the $19^{\text {th }}$ century with the development of industry and international trade began formation of large working village near factories and mines with inadequate housing and the general hygienic conditions. Such a poor way of life imposed a need for ecological thinking about ways how to improve living conditions in order to reduce the social and class tensions, all in function of increasing the labor productivity. Bentham and Malthus' theory were among the first to have sought to link environmental issues with economic effects.

Jeremy Bentham advocated improvement of living conditions for workers in the settlements, characterized by a high density of habitation, poverty and poor hygienic conditions. He claimed that creation of the green parks, improvement of sanitation and more comfortable apartments, would trigger greater interest for work in factories and mines.

Thomas Robert Malthus, contrary of Bentamona, drew attention to the problems of human population growth. He claimed that population grows by geometrical progression whereas food production is arithmetically increased, which leads to deeper gap between number of population and available resources for life. Guided by this perception, he proposed imposing the 
childbirth limitation in working families and other lower social strata.

Serious objections may be made to Malthus attitude for favoring the wealthy social classes at the expense of the poor. Despite theoretical and practical opposition to this theory by the Marxist way of thinking, ideas of Maltusas are actual even now for seeking solutions to the problems of growing population amongst the poor in the world.

In countries with a high standard, the current government are faced with a number of incentives in the form of subsidies and other material benefits aimed at increasing the birth rate. Population growth must be in line with available resources and other possibilities for its survival. The views of Malthus, were scientifically refuted by Karl Marx, the philosopher of the $19^{\text {th }}$ century, through his research work and his simple view that the production of means of consumption practically is unlimited and is harmonized with the law on survival of the matter.

From the late $19^{\text {th }}$ century until the second half of the twentieth century, there was no comprehensive theoretical concept which dealt specifically with environmental problems and consequences of economic and overall social development, even though the need for this was imposed precisely by the process of industrial growth and its impact on the balance in nature. The second half of the $20^{\text {th }}$ century was characterized by the problem of pollution, but also the problem of environmental protection. The ecological - geographical determinism. ${ }^{[2]}$ was created. Hypothesis provides a physical environment for a major determinant of the level of economic development of the country.

Technological innovations in the field of transport, chemical industry, energy, raw material processing, etc., came to the fore by the advent of the economic theory of mass production. Approach to this theory led to extensive use and exploitation of natural resources and to increased environmental degradation. Pesticides have become the first products that were in the dock. In 1952 Rahel Acason was the first one who pointed out to the dangers caused by excessive use of pesticides.

Researches made during the ' 70 s of the last century by the Club of Rome resulted in appearance of 'global balance'. Reports on research results submitted in 1970 under the name "World dynamics and other reports", and in 1972 called "The Limits to Growth" covered the most important elements of life on Earth, namely: population, industrial production, natural resources, raw materials, agricultural production and environmental pollution. The prevailing idea is that it is not possible to exercise unlimited economic growth on limited space and with limited resources.

Primary relations in economic terms can be represented as: the degree resource exploitation can only be less than or equal to the total available resources [4].

The Club of Rome has considered more opportunities for future development with the initial assumption that the economic system and social values will remain unchanged.

Stockholm Declaration from 1980, presented to worrisome state of environmental quality and appealed to all countries to work together to preserve the planet's capacity to produce and renew natural resources $\$$. The principles of conservation the natural resources of the earth and

\footnotetext{
* Expansion of learning and commitment begins for the sake of sustainable development. According to civic learning it "means maximizing net benefits of the economic development that depends on maintaining the service and quality of natural resources over time. Economists who advocate environmental protection and presented this concept in the 1980s, meant the use of renewable natural resources at a pace that is slower than the pace of their recovery, and the use of non-renewable resources with optimum efficiency, taking into account the possibility of substitution the natural resources with technical progress.
} 
environmental protection were advocated, including care for the coming generations.

It is necessary to facilitate and accelerate transition from predominantly industrial production to the production of services relying mainly on resources of knowledge, ie. accelerated transition to post-industrial stage of development. World forecasts show that after 2020, $80 \%$ of people will be working in the tertiary services and information, and only $20 \%$ in primary and secondary services. This prognosis is given as a form of evidence of autonomy, as one of the characteristics of the environmental movement, because such a shift of employment, will necessarily result in a high degree of production system determination, which will be both technical and technological and ecological systems; Production systems will operate according to predefined software [6] and social reforms occur as a need that should allow smaller, local communities and individuals to care more about their environment and to contribute more to increasing global environmental awareness.

Bergen Declaration proclaimed in 1989 the concept of sustainable development. It was presented as a special concept at the United Nations conference in Rio de Janeiro in 1992. This concept basis its validity on the principle of intergenerational equity. Current generation has no right to leave in legacy a damage inflicted to the environment to the future generations, or to leave future generations without the resources that it exploited for itself. Future development, by the rule, will depend on adjustment with the possibilities of biosphere and its eco-systems, as well as the behavior of people in the areas of their performance.[4]

This dynamic or permanent sustainable development implies harmonization of economic development with the principles of social justice, not only at local and national level, but also on the global international milieu. Permanently sustainable develop- ment implies a transition from the classical market economy to ecological economy, as a market economy encourages the irrational use of resources, considering natural resources unlimited and free. The concept of continuous dynamic - sustainable development will be considered as continuous use of limited energy resources, resources, and limited space for development of economic goods production.

State of balance is an assumption for existence of this concept and it is only possible with adequate development of scientific and technological progress. Namely, non-accumulated resources (non-renewable), unlike the accumulated (renewable) resources can be renewable through the scientific and technical materialization and according to the law on the survival of matter.

For instance, waste is only now defined as substances that are found on the site unsuitable for them. Recycling and recovery are unconsciously attached to ecological progress and preservation of equilibrium of the environment. Waste in the production of steel, paper, glass participate, depending on the level of organization of their collection, selection and processing, from $35 \%$ to $65 \%$ in developing countries.

Radical changes in the technicaltechnological and socio-economic systems are created under the influence of technical progress. Technical progress, which has a universal characteristic of diffusion does not bypass any of the areas of economic and social activities. This dual effect of technical progress is manifested in the affirmation of new products, new technologies, new knowledge ... and simultaneous devaluation of existing products, technology, and knowledge. The task of dynamic-sustainable development is in fact to reconcile what is irreconcilable. In this affirmation and devaluation under the influence of technical progress, the advent of ecological principles receives special importance. Simply put, it is 
easier and more effective for every technical and technological change to incorporate and environmental requirements in it, so the efficiency of output and its quality will be dominant in relation to the previous level of output, regardless of the quantity and value of resources consumed and engaged workforce.

Human activities are most detrimental to the functioning of the natural balance in the environment. Those who care for the environment and human health deem that the most visible sources of pollution lie in the industry.

Today we need an active rather than a passive protection of the environment. Achievements of the scientific and technological development may significantly contribute to the application of active methods. Trends indicating absolutely closed systems, point out that the process of metamorphosis will take place according to a pre-defined software, including the selection of an organized waste collection to ensure their recycling and bringing in raw material. This process is a set of active methods aimed at protecting the environment. Intensive protection largely depends on the achieved level of technological development, institutionalized and implemented standards of environmental protection. The proper implementation of standards and scientific-technological achievements, the process itself eliminates the environmental problems and promotes a clean, healthy environment.

Application of modern techniques is a crucial prerequisite for resolving the current problems of environmental protection. The main aim to integrate environmental protection into all phases of the production cycle from production to waste disposal. Upcoming trends emerge as a readiness of actors in the processes of reproduction to accept innovation. One type of preventive care may be the reconstructions or changing of polluting technologies for so-called clean technologies. Thus, the possibilities of environmental protection can be: a method of passive character that reduce harmful effects and methods of active operation through extensive and intensive access to radiation of harmful substances. As a rule, prevention is much more effective than the other methods. Conclusion is made according to the analogy with the health care of the population. If the ecology is in function of health and the health of nation is on the first place on a matrix of values in a society, it follows that all issues related to ecology cannot have a ban at their setting.

Today, there is no economy without the emission of waste, however, the process of "acceptance" of waste processing and its return to the reproduction process is taking place, which is one of the most important environmental and economic factors, as well as priorities in terms of the law of limitations in the availability of certain types of resources. It is exactly a new dominant technology, with high level of production and economic efficiency, that will act as a substituent for the quantity and quality of available resources. The first primary elaboration of the theory of limitation was given by Richard, which was then taken by Marks who included it into his scientific method, and then it later became generally accepted bourgeois way of thinking of modern economics when it comes to the theory of resources.

Preventive measures can be formulated in various ways depending on whether certain methods deal with harmful substances or energy. For practical reasons, this prevention in most cases leads to higher savings, which compensates for the increased cost of the any new investment, be in reconstruction or revitalization. As an evidence to the given claims, the program of preventive protection Minnesota Minningand Manufacturing (briefly three M) Pollution, Preventions, Pays, in short 3P 3P $+)$ is given. In period between 1975 and 1992, three M eliminated more than 575 
thousand tons of waste materials around the world in 3500 successful projects, whereas the application of the cumulative cost savings projects kept up to 573 million dollars in the first year.

The claim that environmental technologies compared to commercial ones do not need to lag behind in economic effects, on the contrary, be dominant, is proven by the experience of Harry Edwards, a professor at the University of Colorado, whose work in the field of reducing environmental pollution achieved the following results from 39 projects for minimization of waste: mean annual savings amounted to an average of 31,581 dollars. One-off costs of implementation amounted to 33.105 dollars which means that the profitability of the project is proved almost as early as the first year of activating investments.

One system is better than another for as much as to it manages to provide a greater degree of rationality in decision-making process. [8] Starting from this attitude, more economical and more efficient use of raw materials and energy will prove to be favorable for the environment, because it slows down the pace of extraction of natural resources, extending their lifespan exploitation, reducing the waste generated, wastes and emissions of harmful substances, just reduced environmental burden. Incorporation of prevention as a way of behavior in the production process, creates an objective protection that is integrated both into the tasks, but also in the minds of employees. Prevention is easier to work, enforcement and continuous improvement of attitude towards the environment.

Economy and ecology have a common interest. For instance, in countries where the cost of handling waste are high and raw materials are expensive, the consumers have raised awareness and laws on the protection are strict, so it is worth organizing cleaner production. Where these conditions are not present, it is typically better "to use the crowd," or insufficient normative regulations and patience of the population.

The cultural aspect is a predominant for ecological way of thinking, because if there are not strong oral arguments besides motivation for profit in decision-making process, then in a longer time projection lots of damage will be inflicted within society itself and in the natural environment. It turns out that emotions are not a good ally for the reason!? Complementary is missing? Capital has no soul! The question which then can be asked is the ratio of the economy and morality. The solution lies in the legal regulation and control. In order to avoid methodological disagreements, it is necessary to define objectives of economy in the case of organizations created for the realization of economic goals. By obtaining credibility, it can be affirm advantages of those companies that will leave traces in the protection of the environment.

If the existing industrial and other economic activities, which now exist under certain conditions, would be stopped, total chaos would be caused in the functioning of the organizational and general social systems existing in organized societies. If production of food, energy and other resources, be it a final or production consumption, was stopped, it would lead to endangering the existence of masses of people.

Therefore, the retention of the existing structure of production and services is subjected to specific selection, because the environmental pollution is considered lesser evil than "production shortages." The advent of new technologies is usually gradual and continuous, mainly also due to the fact that an sudden growth and development "hardendfastlines" are not possible. Continuity is ensured by the achievements of technical progress and the development of competition. Nano technology era is approaching. digital Darwinism is coming. Their main role is consisted of reducing resource consumption leading to their delimitation 
and the effects of Nano technology are becoming generally acceptable, because the quality of the output is gaining absolute environmental characteristics. Performance of nano technology will significantly increase productivity, and other principles of economy occur with the affirmation of the power of technical progress and competitiveness, which is primarily the economy. There are advantages in costs and the costeffectiveness for reasons of reducing capital employed. Thus, it creates threefold objective: rational exploitation of natural resources, increase of economic effects and protection against environmental pollution. The degree of technological process determination and the organization of its functioning plays a dominant role.

Moral thinking of this moment is opposite to the profit, however, the political decisions and institutions are obliged to reconcile and harmonize these two irreconcilable approach. Solution is seen in the affirmation of a higher degree of knowledge and recognition a new dominant technology. It will be shown that the prevention of eco-system destruction is more profitable that pollution control; the waste reduction through recycling and reuse, which has already been proven, is more profitable than disposal of waste and controls on certain depots.

\section{CONCLUSIONS}

Nowadays, there is an uncritical approach to the importance of markets in the economic aspects of the overall economic trend functioning. The role of the market is too exaggerated. Neither privatization, nor the free market, will solve the accumulated problems of individual economies and the global economy. Technology will, rather than the market, considered by economists for many years as a residual factor, influence the direction and pace of economic development. The time for "creative destruction" is coming, which confirms the above given attitude on the dual effect of technical progress.

The action is an attempt to solve strategic forecasted phenomena for planning, flexibility, so that the uncertainty that has characterized the future may be limited.

The present superiority of the market as a mechanism of allocation should be seen only as a temporary nature despite the fact that many authors (Michaelis, Bratsch, Stavins, Grumbly, and others) insist on the need of such a conception of nature protection measures that would minimize their planned character !?

Along with the action, there is an incarnation, which represents a commitment, joint assume of the obligations, projects and common values on the path towards maximizing the objective function. The anticipation, action and incarnations are part of the same organism. Together they imply a synergistic effect, interconnection and interdependence; furthermore, they form a strategic culture, which as such is a key variable in determination of the performance of routing prognostic statements and development.

Platitudes about the free market should be quickly demystified, because the market and the media everywhere in the world are free only as long as they are allowed. The standards and absolute organization are imposed, meaning that there is no freedom of choice in such case.

Specification of market economic instruments for environmental protection is essentially a commitment to their greater affirmation that can be opportunistic from the position of desired effects: maximizing the overall social economic efficiency and maximizing performance to achieve environmental protection. The results achieved 
by applying these instruments may be used to support this claim. Through widespread use of reforming deposits in a series of modern developed economies there has been an improvement in environmental protection and the increase of economic savings. The quality of output is the result of technological performance.

Comparative use of economic and noneconomic instruments appears as the basis of realization of the dynamic - sustainable development concept. This concept, as a rule, leads to the unification of economic and environmental objectives of social development that occurs as a necessary for two key reasons: application as a theoretical and methodological.

Economic or market-based instruments, can act as an adjustment through the price increase use of specific natural resources, work space or quality of the natural environment to be paid by a specific user and which, then through the market, influences the choice of methods of exploitation and the volume of pollution.

Penal policy or refundable deposits through certain licenses cannot be a substitute for the advent of modern technologies. Here there are opposing views of experts. Some advocate for individual property rights, others are in favor of legal judicial coercion, the third are for valorization the economic output, some are for environmental effects that would be higher than they are today, and so on. Wide variety of view, theoretical interpretations, as well as practical actions, which appear as partial performances, are canceled by complex technical and technological development, which is predominant in the selection of appropriate solutions. The question is whether more knowledge and technology or less knowledge and technology? The answer is: not less knowledge but more knowledge, not less technology, but more technology, be cause in this way, by facing problems directly and solving them, we are liberated from destiny.

\section{REFERENCES}

[1] Nefiodov L. A., Der sechte Kontratieff, Rheim-Sieg, Sankt Augustin, 2001, taken: Zelenović M. D., Intellectual Enterprising, Basic Technology of a Serious Society, Prometej, Novi Sad, 2011, p. 59.

[2] Pearce D. V., MacMillan Dictionary of Modern Economics 4 ed., 2003, p. 90.

[3] Todosijević R., Projection, Modern Administration, Belgrade, 1984, p. 18.

[4] Todosijević Lazović S., New Production Programs, Capicity of Production Growth and Economic Efficiency of Companies, Doctoral Thesis, University of Novi Sad, 2010. p. 257.

[5] Todosijević Lazović S., Milačić S., Todosijevic R., Acta Economica No. 24; Faculty of Economy Banja Luka, Scientific Researches and Horizons of Knowledge, 2016, p. 107, p. 115.

[6] Todosijević R., Strategic Management, Volume 1. Faculty of Economy Subotica, 2010, p. 511.

[7] William L. and John P. Powelson, The Role of Technology:An Analysis, New Perspectives on Development, 1981, p. 20.

[8] Winer Norbert, Cybnstiernetics or Control and Communication in the Animal and the Machine, Massachusetts Institute of Technology, 1948.

[9] Todosijević R., To Successful Company Through Changes, Prometej, Novi Sad, 1986.

[10] Zelenović M. D., Intellectual Enterprising, Basic Technology of a Serious Society, Prometej Novi Sad,. 2011, p. 52.

[11] www.diapat.com 
[12] www.zeiss.de

[13] www.ident-technology.de

[14] www.dkfz.de

[15] www.cbs.mpg.de

[16] www.klinikum.uni-heidelberg.de

[17] www.gkss.de

[18] www.osram.de
[19] www.Imu.de

[20] www.tu-braunschweig.de

[21] www.biokon.net

[22] www.iaim.ira.uka.de

[23] www.uni-stuttgart.de

[24] www.neuraxo.de

[25] www.dir.de 